\title{
DETAILED ELECTROPHORETIC ANALYSES OF SERA OF HEALTHY YOUNG MEN ${ }^{1}$
}

\author{
By EDWARD R. BERRY AND ALFRED CHANUTIN \\ (From the Department of Biochemistry, School of Medicine, University of Virginia, \\ Charlottesville, Va.)
}

(Submitted for publication May 5, 1955 ; accepted June 15, 1955)

The electrophoretic patterns of plasma and serum obtained from healthy individuals have been described by a number of investigators and the results of such analyses are summarized in a recent paper (1). Appreciable fluctuations in the concentrations and percentage distributions of the major protein components are noted. A critical examination of these data shows that workers in this field use a variety of buffer solutions with different ionic strength and usually average the results obtained for males and females in different age groups. Furthermore, Bernfeld, Donahue, and Homburger (2) have observed large variations in the general appearance of electrophoretic patterns and have emphasized the necessity of considering the finer structures of the contour in the analytical procedure.

The data obtained from electrophoretic analyses depend on the method by which the area of the electrophoretic pattern is subdivided. The analysis of electrophoretic patterns of serum proteins is generally done by the procedure of Tiselius and Kabat (3) which involves drawing a perpendicular from the base line to the minimum between two peaks, or the components may be resolved by drawing a series of symmetrical curves as described by Svedberg and Pedersen (4). The method of Tiselius and Kabat has the advantage of simplicity and the results approach those given by the Pedersen procedure $(5,6)$. Wiedemann (7) subdivided the electrophoretic areas of sera with the aid of Gaussian curves and stated that nine components could be distinguished.

Because of the wide discrepancies in values for normal plasma and serum, it was of interest to analyze in detail electrophoretic patterns which were obtained under carefully controlled conditions. This paper presents the results of electrophoretic analyses of sera from healthy young men.

1 This investigation was supported by a research contract V1001M-1074 with the Veterans Administration.

\section{METHODS}

First year, male, medical students, ranging in age from 20 to 25 years, served as subjects during the period from February 1 to May 1, 1952. These students had finished their final examinations in Anatomy on January 30. The subjects were selected at random and no attempt was made to pick any individual at any given time. In several cases, brothers who were in the College were used as subjects. Care was taken to avoid obtaining blood from individuals with respiratory, alimentary or other disorders. Blood was drawn before breakfast and the serum was separated within two hours. Serum $(0.85 \mathrm{ml}$.) was diluted with $2 \mathrm{ml}$. barbiturate buffer ( $\mathrm{pH} 8.6 \pm .02$, ionic strength 0.1 ) and dialyzed in the cold against three changes of the buffer solution during a period varying from 18 to 30 hours. Electrophoresis was done in a Klett Model of the Tiselius apparatus using a microcell of $2 \mathrm{ml}$. capacity. The temperature of the bath was maintained at $2.0 \pm 0.01^{\circ}$. Electrophoresis was allowed to proceed at $7 \mathrm{ma}$. (10 v per $\mathrm{cm}$.) for about 100 minutes until the distance between albumin and the $\delta$-boundary approximated fixed positions marked on a celluloid sheet at the viewing screen. The picture was taken by Longsworth's scanning technique (5) immediately after the current was shut off. The conditions of illumination, dilution of the serum, dialysis, buffer solution and exposure of the plate were carefully controlled. The ascending patterns were analyzed. Tracings of the pattern, magnified four times, were made on coordinate paper and included the base and the edges of the picture. The position of the pattern in the enlarger was always the same and precautions were taken to avoid parallax. When necessary, corrections for the defects of the optical systems were made from the respective base lines.

Ordinarily, the absolute mobilities of protein components in an electrophoretic pattern are determined by measuring the displacements from the starting boundary. The accuracy of such determinations depend on protein concentration (8), the time of electrophoresis, absence of leaks in the system, electro-osmosis, density inversion, and the influence of conductivity and $\mathrm{pH}$ gradients in the solution during electrophoresis. The relative influence of some of these factors on the migration and concentration gradient of a component cannot be properly evaluated; however, variations are minimized by carefully controlled experimental procedures. Values for absolute mobilities of individual components, obtained under routine conditions, show considerable variations. On 
TABLE I

Relative rates of migration of mean boundary positions and their respective leading limits at base line

\begin{tabular}{|c|c|c|c|c|c|c|c|c|c|c|c|c|c|c|c|c|c|c|}
\hline & Alb. & $\alpha 1^{0}$ & $\alpha_{1}^{1}$ & $\alpha_{1}{ }^{2}$ & $\alpha_{1}^{3}$ & $\alpha 2^{1}$ & $\alpha 2^{2}$ & $\boldsymbol{\beta}^{\mathbf{1}}$ & $\beta^{2}$ & $\beta^{3}$ & $\beta^{4}$ & $\tau$ & $\gamma_{1}$ & $\gamma_{2}$ & $\gamma_{2}$ & $\gamma_{4}$ & $\gamma_{b}$ & \\
\hline $\begin{array}{l}\text { Boundary } \\
\text { Limit }\end{array}$ & 6.00 & $\begin{array}{l}5.56 \\
5.68\end{array}$ & $\begin{array}{l}5.36 \\
5.68\end{array}$ & $\begin{array}{l}5.12 \\
5.36\end{array}$ & $\begin{array}{l}4.93 \\
5.43\end{array}$ & $\begin{array}{l}4.36 \\
4.88\end{array}$ & $\begin{array}{l}3.95 \\
4.43\end{array}$ & $\begin{array}{l}3.63 \\
3.82\end{array}$ & $\begin{array}{l}3.34 \\
3.67\end{array}$ & $\begin{array}{l}3.05 \\
3.42\end{array}$ & $\begin{array}{l}2.75 \\
3.05\end{array}$ & $\begin{array}{l}2.45 \\
2.75\end{array}$ & $\begin{array}{l}2.13 \\
2.45\end{array}$ & $\begin{array}{l}1.79 \\
2.13\end{array}$ & $\begin{array}{l}1.48 \\
1.79\end{array}$ & $\begin{array}{l}1.22 \\
1.50\end{array}$ & $\begin{array}{l}1.02 \\
1.39\end{array}$ & $.646^{*}$ \\
\hline
\end{tabular}

* Trailing limit of $\gamma_{5}$.

the other hand, the values for relative mobilities of these components are reproducible within narrow limits.

Careful analyses of the electrophoretic patterns of a large number of sera and plasmas from healthy and diseased individuals indicated that at least 17 components are present. The relative mobilities of the mean positions and the leading and trailing limits of each component were determined. The value of 6.00 was arbitrarily assigned to albumin, since it approximates the order of the absolute mobility. The remaining values were proportioned to their relative migration rates (Table I).

The following basic assumptions were made for the analysis: (a) all boundaries were considered to be symmetrical; (b) areas responsible for dissymmetry of a boundary were attributable to the presence of another protein; (c) the relative positions of the mean boundaries and their contour "limits" approaching the base line remained constant; and (d) the relative migration rates were independent of protein concentration.

The following procedures are described for delineating the areas of these components. The position where the trailing edge of the $\gamma_{5}-$ globulin boundary apparently ceases its contribution to the $\delta$-area was designated as $A$

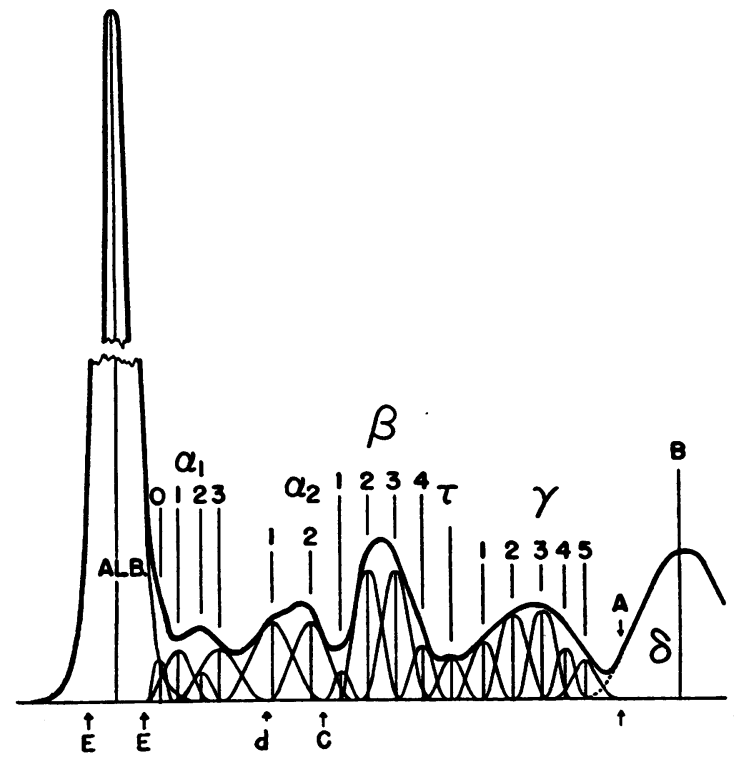

Fig. 1. The Electrophoretic Pattern and 17 Components Constructed from Mean Values of 46 SERa

The significance of symbols are described in text.
(Figure 1) and represents a point where the contour visibly deviates from the tangent drawn through the point of inflection. The distance between point $\mathrm{A}$ and the albumin boundary axis was accurately measured with a metal ruler. From this measurement and from relative mobility values (Table I) for the albumin axis (6.00) and point $\mathrm{A}(.646)$, the zero time position and the positions of the remaining components were readily calculated. The position of the axes of the boundaries and their limits on the base line were accurately marked with a sharp needle on the pattern and all axes and boundaries drawn as thin sharp lines. Needle dividers were used for transposing and for checking the ordinates.

It was found by experience that the analysis of the envelope was most easily accomplished by using the contour ordinates of the limits of $\alpha_{2}^{1}$ - and $\alpha_{2}^{2}$. The details of the analysis and the construction of curves for these two components are shown in Figure 2. The boundaries of these two components were drawn so that the sum of the ordinates of the contributing boundaries equaled the height of the envelope at every point. It is essential that a number of points be used in transposing a segment of a curve.

As a rule, the boundaries for $\beta^{1}-, \beta^{2}-, \beta^{3}$ - and the leading half of $\beta^{4}$-globulins were next resolved. After these analyses, the $\boldsymbol{\gamma}$-globulins were resolved by using the trailing limit of $\boldsymbol{\gamma}_{5}$-globulin as a starting point. If the $\boldsymbol{\alpha}_{\mathbf{2}}$ and $\beta$-globulins and the $\gamma$-globulins are properly analyzed, the trailing edge of the $\beta^{4}$-globulin should be symmetrical to its leading edge, indicating that the positions and differentiation of the respective components are correct. The albumin boundary was obtained by reflecting points on the leading edge about its axis. The residual area between the reflected line of albumin and the envelope contains the $\alpha_{1}^{0}$-component and some of the $\alpha_{1}^{1}$ globulin. The resolution of the $\alpha_{1}-$ globulins completed the analysis of the pattern. The fixed positions of the components determine the solution of the envelope and prevent cumulative errors. The areas of the components were measured at least twice by planimetry. The difference of the sum of the component areas and the total area of the pattern (albumin through $\gamma_{5}$-globulin) should not differ by more than 2 per cent.

Two points ( $E$ in Figure 1 ) obtained by extending the tangent of the slope of the upper third of the albumin envelope to the base line were found to be useful in evaluating the electrophoresis technique. The distance of these points from the albumin axis is uniform with good technique. An increase in the spread of these points, due to a broadening of the albumin boundary, 

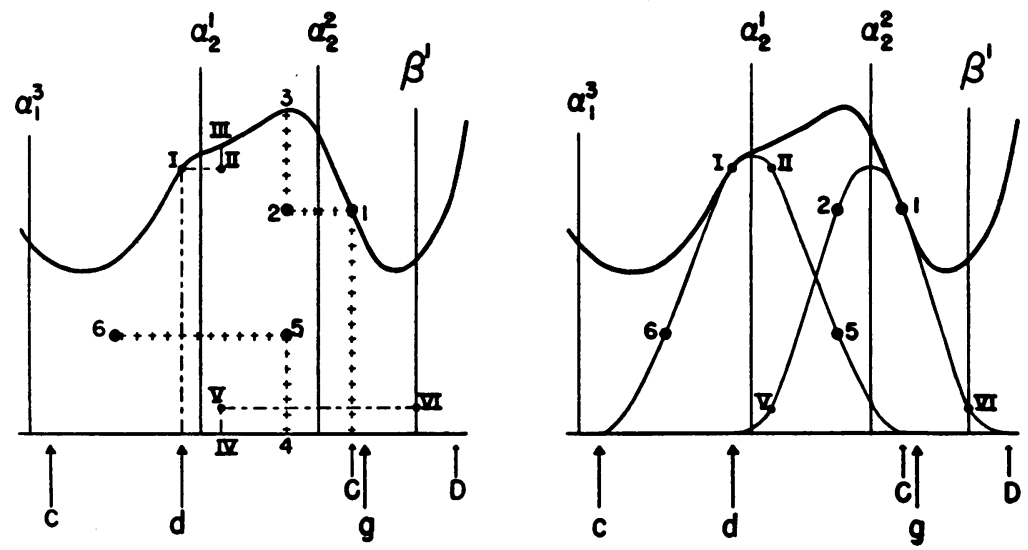

Fig. 2. Details of Analysis and Construction of Curves for $\alpha_{2}{ }^{1}$ - and $\alpha_{2}^{2}$-GLOBULINS

The following symbols are used: $c$ and $C$ and $d$ and $D$ represent the leading and trailing limits of the $\alpha_{2}{ }^{2}$ - and $\alpha_{2}^{2}$-globulins, respectively. $g$ is the leading limit for $\beta^{2}$-globulin. Point $I$ on the envelope is a projection- of $d$ and point $I I$ is obtained by reflection of point $I$ about the $\alpha_{2}{ }^{1}$ axis. The distance $I I-I I I$ is transposed to the base line and is shown as $I V-V$. Point $V I$ represents a reflection of point $V$ about the $\alpha_{2}{ }^{2}$ axis. In a similar manner, point $C$ is projected to the envelope (point 1 ) and the transposition of points is done as described above.

The curve for $\alpha_{2}{ }^{1}$-globulin is constructed from points $6, I, I I$ and 5 with $c$ and $C$ as limits; $\alpha_{2}^{2}$-globulin is drawn through points $V, 2,1$ and $V I$ with $d$ and $D$ as limits. The line between 6 and $I$, for example, is slightly curved and the curvatures near the limits and the peaks change gradually.

is usually caused by a poor starting boundary or by a delay in taking the picture after the current is stopped.

\section{RESULTS}

The individual planimeter values, which were found to give the best indices for relative concentrations, were plotted against days following the examination period. It was observed that the $\alpha_{1}^{3}, \gamma^{1}$ - and $\gamma^{2}$-globulin values were higher during the first 25 days than during the subsequent period. The $\alpha_{2}{ }^{1}$-globulin concentrations were low during the first 40 days and subsequently increased; in contrast, the $\alpha_{2}{ }^{2}$-values were high during this same preliminary period and decreased after this time. Since the most pronounced changes were noted for the $\alpha_{2}{ }^{1}$ - and $\alpha_{2}{ }^{2}$-globulins, the data were separated to cover the first 40 days (group 1) and the 41 to 92 -day period (group 2) and presented in Figure 3. The mean and the variance for each component were not presented because of the skewed distribution of the data. The relationship between $\alpha_{2}{ }^{1}$ - and $\alpha_{2}{ }^{2}$-globulins could be best demonstrated by plotting the ratios of these two components in individual sera against days after examination (Figure 4).

The envelope and the 17 components of an electrophoretic pattern (Figure 1) were constructed from the mean values of the respective areas of 46 sera in group 2.

The electrophoretic patterns of the sera in group 2 were also analyzed by the Tiselius-Kabat method (3). The mean values for the percentage distribution, the standard deviations and the range of values are shown in Table II; additional data for sera, analyzed in barbiturate buffer at $\mathrm{pH} 8.6$, are included for comparison. The values published by Sterling (11) for 10 young men agree closely with the data obtained in the present experiments. The differences in the mean values and the variations about the mean, observed by other investigators, are probably attributable to differences in technique, and to the influence of sex and age on the plasma protein composition.

\section{Influence of family relationship}

Electrophoretic patterns of sera from identical twins, seven pairs of brothers differing from 1 to 


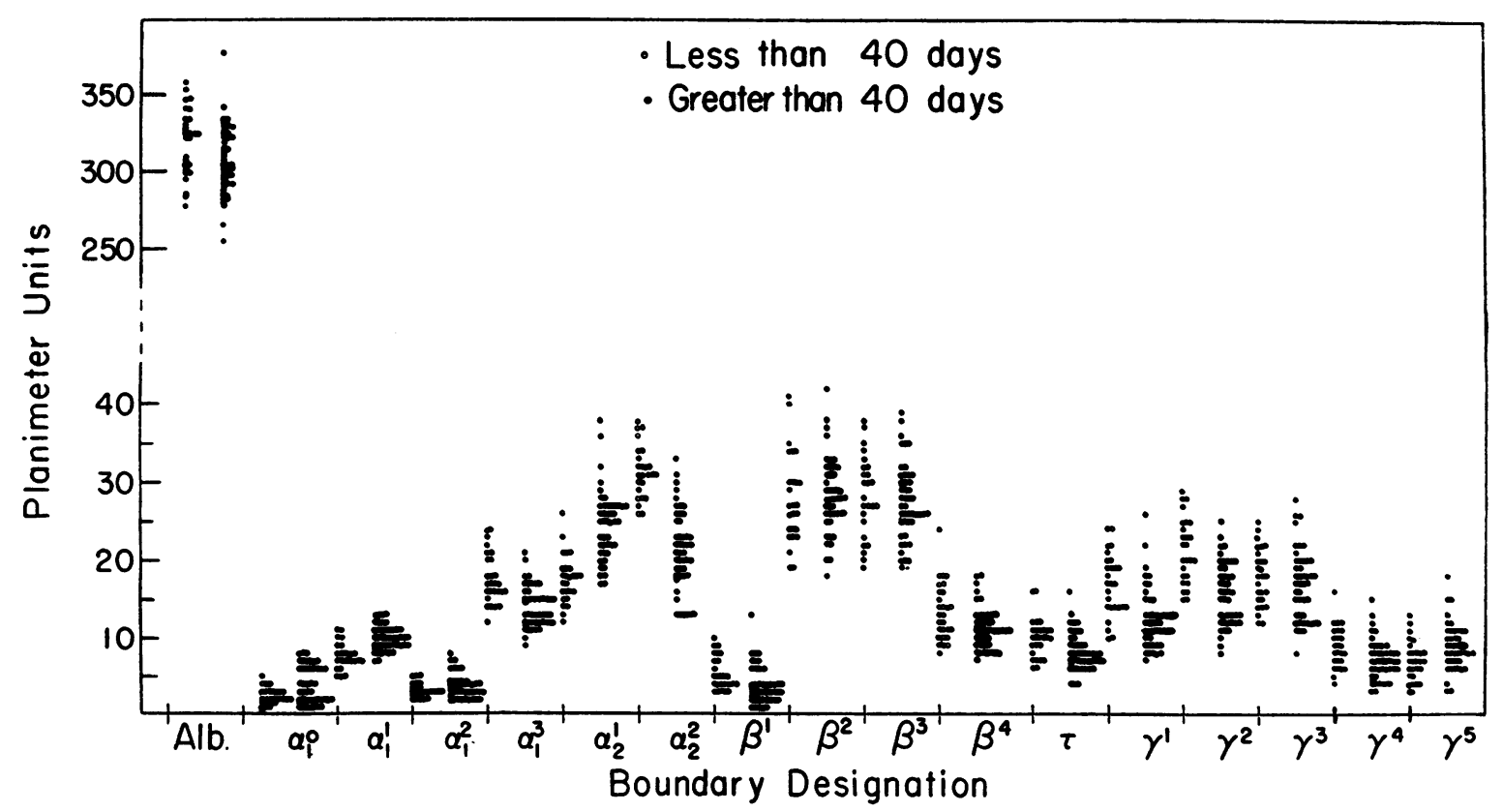

Fig. 3. Individual Concentrations of 17 Components of Serum

3 years in age and a father and son were analyzed. In all cases, samples of blood were drawn from each pair within a few minutes of each other.

Tracings of the electrophoretic patterns for six pairs of brothers are shown in Figure 5. The patterns of the sera from respective brothers show a striking similarity in size and shape of the major components; slight differences in the shape of boundaries may be partly due to the extent of migration of the pattern. A comparison of these patterns and the analytical data between unrelated individuals shows considerable differences.
Two sets of analytical data for identical twins, representing sera obtained two years apart, show that most of the values are in close agreement (Figure 6). Data for five of the seven brothers and $a$ father and his son are presented in Figure 7. The results for the remaining two brothers, which were omitted due to lack of space, were similar to the data presented. The values for $R$. W. and W. W. are almost identical except for one component. In the remaining cases, there is no consistent pattern in the type of component or the differences in concentrations between components

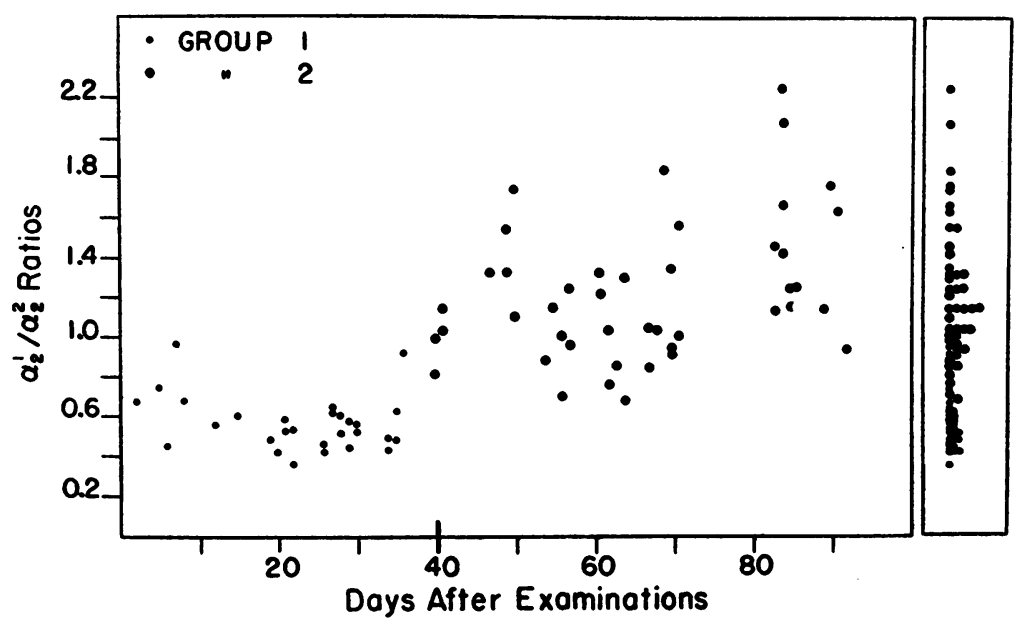

Fig. 4. The $\alpha_{2}^{1} / \alpha_{2}^{2}$ Ratios at Varying Periods after Examinations 
TABLE II

Mean percentage distributions and standard deviations of components of 46 sera analyzed by the Tiselius-Kabat method *

\begin{tabular}{|c|c|c|c|c|c|c|}
\hline $\begin{array}{l}\text { No. } \\
\text { sera }\end{array}$ & Albumin & $\alpha_{1}$ & $\alpha_{2}$ & $\boldsymbol{\beta}$ & $\boldsymbol{\gamma}$ & Reference \\
\hline \multirow[t]{2}{*}{46} & $\begin{array}{l}60.6 \pm 3.5 \\
(53.4-67.6)\end{array}$ & $\begin{array}{l}4.0 \pm 0.6 \\
(2.8-6.1)\end{array}$ & $\begin{array}{l}9.2 \pm 1.5 \\
(6.0-12.8)\end{array}$ & $\begin{array}{l}14.0 \pm 1.6 \\
(10.2-17.9)\end{array}$ & $\begin{array}{r}12.4 \pm 2.7 \\
(7.5-21.2)\end{array}$ & Authors \\
\hline & & & $A / G=1.54$ & & & \\
\hline \multirow[t]{2}{*}{43} & $\begin{array}{l}53.3 \pm 2.6 \\
(47.6-59.2)\end{array}$ & $\begin{array}{l}8.0 \pm 1.35 \\
(5.3-11.5)\end{array}$ & $\begin{array}{c}10.4 \pm 1.38 \\
(7.7-12.9)\end{array}$ & $\begin{array}{c}13.8 \pm 1.89 \\
(7.9-17.6)\end{array}$ & $\begin{array}{c}14.2 \pm 2.68 \\
(8.7-19.7)\end{array}$ & (9) \\
\hline & & & $A / G=1.15$ & & & \\
\hline \multirow[t]{2}{*}{10} & $\begin{array}{l}56.5 \pm 2.8 \\
(53.1-59.8)\end{array}$ & $\begin{array}{l}5.2 \pm 1.7 \\
(4.2-6.0)\end{array}$ & $\begin{array}{l}9.0 \pm 1.4 \\
(7.8-11.4)\end{array}$ & $\begin{array}{l}15.2 \pm 1.5 \\
(13.7-17.2)\end{array}$ & $\begin{array}{c}14.2 \pm 1.8 \\
(10.6-16.2)\end{array}$ & (10) \\
\hline & & & $A / G=1.30$ & & & \\
\hline \multirow[t]{2}{*}{10} & $\begin{array}{l}60.3 \pm 2.8 \\
(55.0-64.8)\end{array}$ & $\begin{array}{l}4.0 \pm 0.8 \\
(2.5-5.3)\end{array}$ & $\begin{array}{l}9.7 \pm 1.5 \\
(7.3-12.9)\end{array}$ & $\begin{array}{r}12.8 \pm 1.2 \\
(9.9-14.3)\end{array}$ & $\begin{array}{c}13.2 \pm 1.7 \\
(10.4-16.1)\end{array}$ & (11) \\
\hline & & & $A / G=1.52$ & & r. & \\
\hline 80 & $56.2 \pm 2.8$ & $7.2 \pm 1.3$ & $8.8 \pm 1.9$ & $13.1 \pm 2.5$ & $14.7 \pm 2.6$ & (12) \\
\hline
\end{tabular}

* Figures in parentheses represent range in values.

for the respective brothers. It will be noted that the shapes and concentrations of the $\gamma$-globulins are quite similar for each pair of brothers but may differ considerably for unrelated individuals. The phenomenon is particularly striking for the father and son.

\section{DISCUSSION}

The Tiselius-Kabat procedure for analyzing electrophoretic patterns does not consider the con- tour or the effect of the distance of migration (5). Results of such analyses may be misleading, since areas (concentrations) of major components of sera may be similar despite differences in the shapes of the envelopes of the patterns (2). The analytical procedure presented in this paper makes it possible to determine the material responsible for changes in the contour of the pattern. The analysis is time consuming but the results are precise. Duplicate analyses of a serum show that the

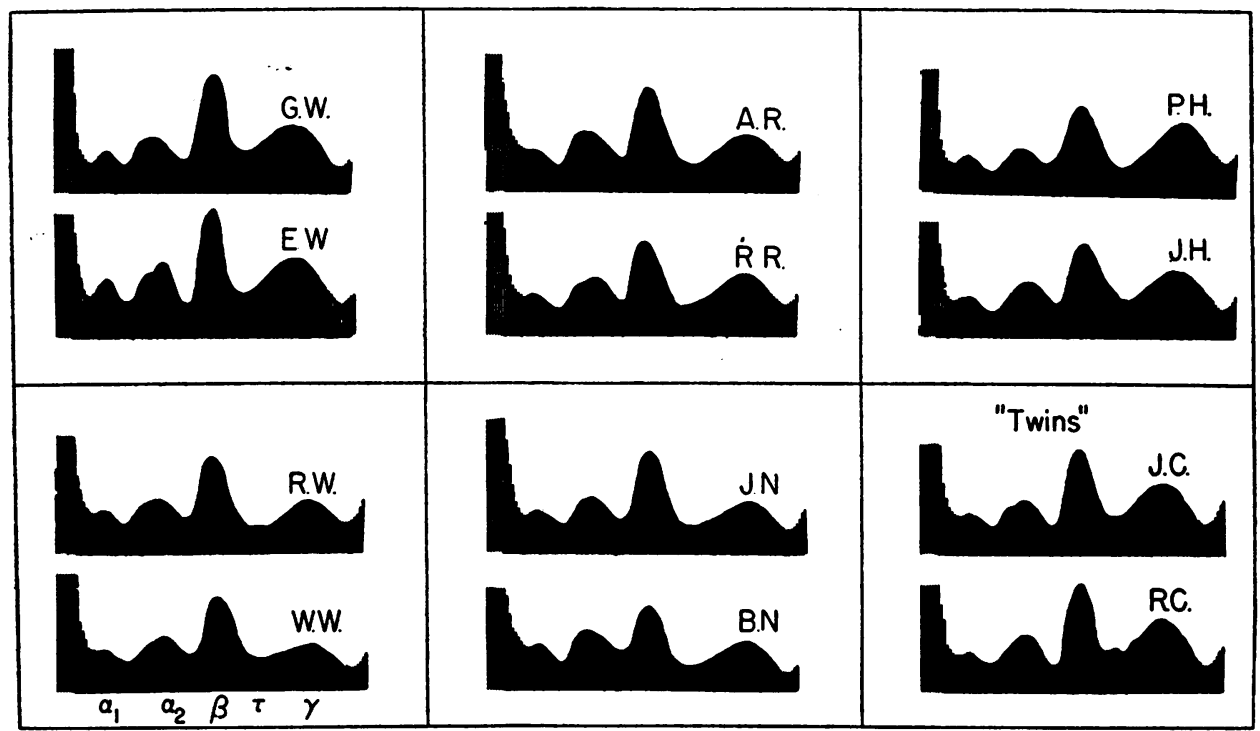

Fig. 5. Electrophoretic Patterns of Six Pairs of Brothers

The solid area represents the globulins and the shaded areas represent the trailing portion of albumin and the leading portion of the o-boundary. 


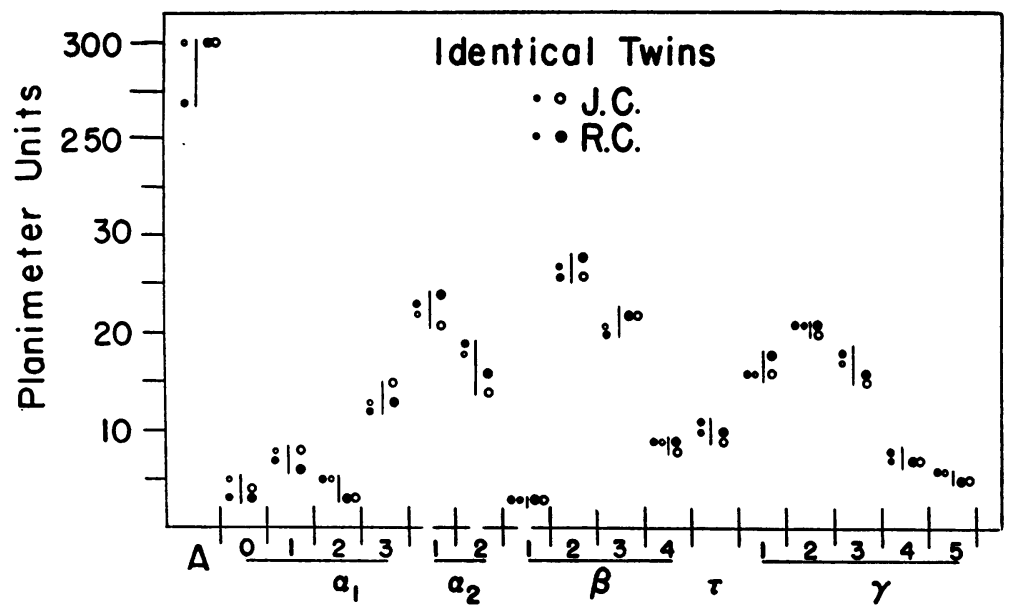

Fig. 6. The Concentrations of Protein Components of Sera from IDENTICAL TWINS

The samples were obtained in February, 1952 (small circles) and February, 1954 (large circles).

concentration for each component is reproducible. This procedure could be particularly useful for determining the finer details in patterns of sera which are being studied during the course of observations in healthy or diseased individuals.

Examination of the contours in Figure 1 will indicate that the variations in values for absolute mobilities obtained by using the peak or the centroidal ordinate of a boundary may be attributed to a shift of the maxima of the peaks due to changes in the concentrations of the components within given areas.

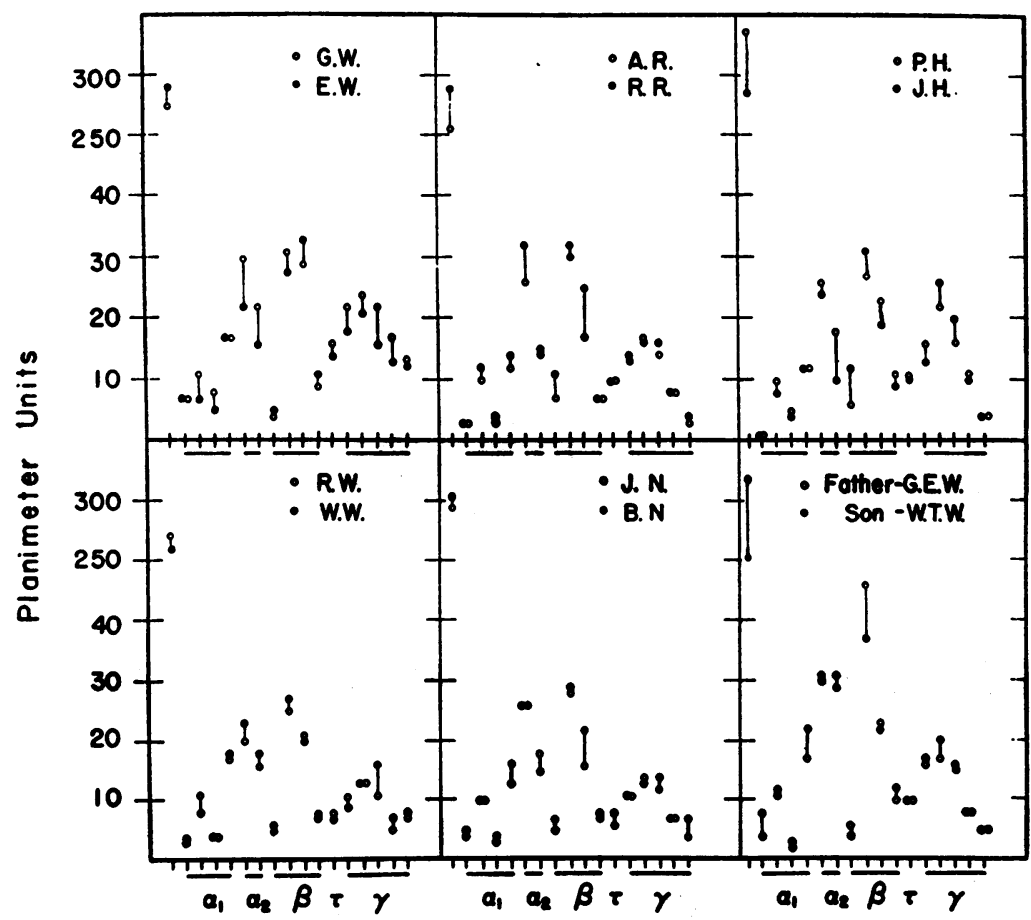

Fig. 7. Comparison of Component Concentrations in Five Pairs of Brothers and a Father and Son 
Since the factors which might affect the ratio of the $\alpha_{2}{ }^{1}$ - to $\alpha_{2}{ }^{2}$-globulins in sera during and after the first 40 days following examinations (Figure 4) are unknown, conclusions concerning the significance of these changes would not be justified. This shift in the concentration of these 2 components occurs early in March and may be associated with climatological conditions. It is suggested, however, that the stress of the examination is responsible for the changes observed.

The consistent finding in this study that the contour of the electrophoretic patterns and the concentrations of the protein components of sera in brothers are similar would indicate that there is a hereditary basis for these observations. It is noteworthy that abnormal globin of sickle cell hemoglobin is transmitted by genes. Although, it may not be directly pertinent to this problem, it is interesting that a strong similarity in the excretion of nitrogenous metabolites was observed between certain siblings (13).

\section{SUM MARY}

A method for dividing the electrophoretic pattern of serum into 17 components is described. The procedure is based on the assumption that each component is symmetrical about its axis and has a fixed relative mobility value. Precautions for accurate electrophoretic analysis and for delineating each boundary are discussed.

In 73 male medical students, single determinations of concentrations of serum protein components were correlated with the elapsed time of about three months after final examinations in Anatomy. The range of concentrations for 15 components did not change appreciably during the period of observation. Significant differences in the concentrations of the two $\alpha_{2}$-globulins, observed during and after the first 40 days, are believed to be associated with the stress of examination.

In brothers, the contours of the electrophoretic patterns of their sera are similar and the values for the concentrations of the respective components are in close agreement. It is suggested that the concentration and distribution of serum pro- teins of young healthy individuals are under genetic control.

The significance of the analytical procedures and the results are discussed.

\section{ACKNOWLEDGMENT}

The authors wish to express their thanks to Messrs. T. Pankey, W. Fleenor, and J. Hardy for technical assistance.

\section{REFERENCES}

1. Young, E. G., and Webber, R. V., On the origin of human plasma proteins: Electrophoretic analyses in selected pathological states. Canad. J. Med. Sc., 1953, 31, 45.

2. Bernfeld, P., Donahue, V. M., and Homburger, F., Characteristic individual electrophoretic patterns in humans. Proc. Soc. Exper. Biol. \& Med., 1953, 83, 429.

3. Tiselius, A., and Kabat, E. A., An electrophoretic study of immune sera and purified antibody preparations. J. Exper. Med., 1939, 69, 119.

4. Svedberg, T., and Pedersen, K. O., The Ultracentrifuge. Oxford, Oxford Univ. Press, 1940, p. 296.

5. Longsworth, L. G., Recent advances in the study of proteins by electrophoresis. Chem. Rev., 1942, 30, 323.

6. Dole, V. P., The electrophoretic patterns of normal plasma. J. Clin. Invest., 1944, 23, 708.

7. Wiedemann, E., Electrophorese-Versuche an Serum und Plasma. 3. Mitteilung. Schweiz. med. Wchnschr., 1946, 76, 241.

8. Lippman, R. W., and Banovitz, J., Influence of protein concentration upon electrophoretic mobility of serum proteins. J. Biol. Chem., 1952, 199, 451.

9. Seibert, F. B., Seibert, M. V., Atno, A. J., and Campbell, H. W., Variation in protein and polysaccharide content of sera in the chronic diseases, tuberculosis, sarcoidosis and carcinoma. J. Clin. Invest., 1947, 26, 90.

10. Cohen, P. P., Thompson, F. L., and Nitshe, G. A., Jr., Electrophoretic analysis of ante- and postmortem serum in different diseases. J. Clin. Invest., $1947,26,820$.

11. Sterling, K., The serum proteins in infectious mononucleosis. Electrophoretic studies. J. Clin. Invest., 1949, 28, 1057.

12. Reiner, M., Fenichel, R. L., and Stern, K. G., Electrophoretic studies on the protein distribution in normal human serum. Acta Haemat., 1950, 3, 202.

13. Berry, H. K., and Cain, L., XVIII. Individual urinary excretion patterns of young children. Biochemical Institute Studies IV, Austin, Univ. of Texas, 1951, p. 165. 